\title{
Puberty Menorrhagia Requiring Inpatient Admission
}

\author{
Khosla AH, ${ }^{1}$ Devi L, 'Goel P, Saha PK' \\ 'Department of Obstetrics \& Gynaecology, Government Medical College and Hospital, Chandigarh, India.
}

\section{ABSTRACT}

Introduction: Puberty menorrhagia is a significant health problem in adolescent age group and severe cases may require admission and blood transfusion. Aim of this study was to evaluate the causes, associated complications and management of puberty menorrhagia.

Methods: Hospital records of all patients of puberty menorrhagia requiring admission were analyzed for etiology, duration since menarche, duration of bleeding, investigation profile and management.

Results: There were 18 patients of puberty menorrhagia requiring hospital admission. Etiology was anovulatory bleeding in 11 patients, bleeding disorders in five which included idiopathic thrombocytopenia purpura in three and one each with Von-Willebrand disease and leukemia. Two patients had hypothyroidism as the cause. Fourteen patients presented with severe anaemia and required blood transfusion. All except one responded to oral hormonal therapy.

Conclusions: Puberty menorrhagia can be associated with severe complications and requiring blood transfusion. Although most common cause is anovulation but bleeding disorder, other medical condition and other organic causes must be ruled out in any patient of Puberty menorrhagia.

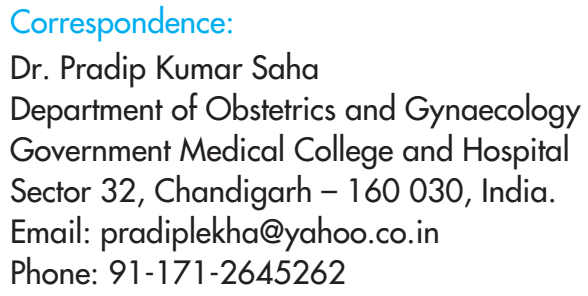




\section{INTRODUCTION}

Puberty menorrhagia is defined as excessive bleeding occurring between menarche and adolescence. It can pose a significant challenge to the gynecologist and can be associated with serious systemic complications like anaemia, hypoproteinemia requiring

indoor admissions and blood transfusion. $80 \%$ of puberty menorrhagia is caused by anovulatory cycle ${ }^{1}$ as a result of immaturity of the hypothalamic pituitary ovarian axis in the first several years after menarche. ${ }^{2,3}$ Beyond this time, menstruation usually become more regular and bleeding normalizes. ${ }^{4}$ Congenital or acquired bleeding disorder are the cause of menorrhagia in $19-25 \%$ of the cases.

In persistent abnormal bleeding and in patients with mucocutaneous bleeding, coagulation disorders and leukemia should be ruled out. An organic disease or malignancy in particular is a rare cause of puberty menorrhagia. In all cases it is mandatory to exclude pregnancy. We carried out this analysis with the objective to find out the incidence, complication, etiology and role of conservative management in the puberty menorrhagia.

\section{METHODS}

A four year retrospective analysis of all patients requiring admission for critical puberty menorrhagia was carried in Govt medical college and hospital, Chandigarh from January 2002 to December 2005. Data was collected from medical records of these patients.

Each patient's record was analyzed for demographic profile, duration and severity of symptoms, age of menarche, past and family history of bleeding disorders, requirement of blood and component transfusion and response to therapy. The baseline investigation included exclusion of pregnancy, complete blood count, peripheral smear, blood grouping and typing and transabdominal ultrasonography (USG). Specific investigations i.e. thyroid function test, follicle stimulating hormones (FSH), luteinizing hormone (LH), bone marrow etc. were done in selected cases.

\section{RESULTS}

There were 18 patients with puberty menorrhagia requiring indoor admissions among 106 making an incidence of $16.9 \%$ of admissions for adolescent girls. Most of the patients (83\%) were in the age group of 11-16 years. Duration of menarche was less than one year in 10 patients. Fourteen patients presented with history of menorrhagia since less than six months and eight patients required admission at first episode. Onset of menorrhagia since menarche was present in six patients (Table 1).

Anovulatory dysfunctional bleeding occurred in $61 \%$ of the cases. Five patients (27\%) were diagnosed with bleeding disorders. Of these three patients were diagnosed with idiopathic thrombocytopenic purpura (ITP) and one patient was diagnosed to be suffering from leukemia and one had von-Willebrand disease. All three patients of thrombocytopenia presented with severe anaemia (Haemoglobin $1.5 \mathrm{gm} \%$ - $2 \mathrm{gm} \%$ ) also had history of severe heavy menstruation since menarche. Two of these patients had history of multiple blood transfusion at previous admissions in private nursing home where this diagnosis was not considered. One patient of chronic Idiopathic thrombocytopenic purpura (ITP) not responding to steroids underwent splenectomy. Patients with Von-Willebrand disease presented with severe anaemia (Haemoglobin $4.5 \mathrm{gm} \%$ ), history of purpura and ecchymotic patch since childhood and received blood transfusion twice in the past but diagnosis was made only after investigations in the higher institute. Patient with acute myeloid leukemia presented with high grade fever menorrhagia and bleeding from other sites. Two patients had hypothyroidism as the cause of menorrhagia and of which one patient also had features of overt hypothyroidism i.e. coarse dry skin, cold intolerance, hoarse voice, bradycardia and delayed ankle jerk. Three patients showed features of polycystic ovaries on ultrasonography but none of these patients had signs of hyperandrogenemia and no further investigations were done to rule out hyperandrogenism.

Fourteen patients $(77 \%)$ presented with severe anaemia at admission. Seventeen patients (94\%) required multiple blood transfusions. Four patients required blood component in the form of platelet rich plasma and fresh frozen plasma.

Fifteen patients received high dose oral contraceptive pills (OCPs) and three patients responded to progestogens. Tranexaemic acid was used in six cases along with hormonal treatment. Patient suffering from leukemia was referred to haematology and was given chemotherapy and menorrhagia was controlled on OCPs (Table 2). Both the patients with hypothyroidism initial bleeding was controlled on OCPs and thyroxin replacement therapy was started.

Table 1. Age, duration of menarche, duration of bleeding

\begin{tabular}{cc}
\hline Age (years) & No. \\
\hline $10-12$ & 04 \\
$13-14$ & 04 \\
$15-16$ & 07 \\
$>16$ & 03 \\
\hline
\end{tabular}

\begin{tabular}{ll}
\hline II. $\quad$ Duration of Menarche & \\
\hline$<6$ months & 02 \\
6 months -1 year & 08 \\
1 year -2 year & 05 \\
$>2$ year & 03 \\
\hline
\end{tabular}

\begin{tabular}{|c|c|c|}
\hline III. & Duration of menorrhagia & \\
\hline & First episode & 08 \\
\hline & $3-6$ months & 06 \\
\hline & 6 months -1 year & 04 \\
\hline
\end{tabular}




\section{DISCUSSION}

Normal menstrual blood loss is defined as blood loss of less than $80 \mathrm{ml}$ and the normal cycle length varies from 25-35 days. However, at puberty for initial five years after menarche anovulation arises from lack of maturity of hypothalamic-pituitary-ovarian-axis ${ }^{2,3}$ leading to immature timing of LH pulse as well as increase basal levels of LH results in anovulatory cycles. These cycles are characterized by levels of FSH and LH that are sufficient to induce follicular development and induce estrogen secretion but inadequate to induce follicular maturation and ovulation. Unopposed estrogen stimulates endometrial growth which outgrows its blood supply and architectural support, resulting in partial breakdown and shedding in irregular manner. ${ }^{6}$

\section{Table 2. Aetiology, Investigation, Management}

\begin{tabular}{ll}
\hline I. Aetiology & No. \\
\hline Anovulatory cycles & 11 \\
Idiopathic thrombocytopenic purpura & 03 \\
Von-Willebrand disease & 01 \\
Hypothyroidism & 02 \\
Leukemia & 01 \\
\hline
\end{tabular}

\begin{tabular}{|c|c|c|}
\hline II. & $\begin{array}{l}\text { Investigation } \\
\text { Haemoglobin levels }\end{array}$ & \\
\hline & $<6 \mathrm{gm} / \mathrm{dl}$ & 05 \\
\hline & $8-10 \mathrm{~m} / \mathrm{dl}$ & 02 \\
\hline & $>10 \mathrm{gm} / \mathrm{dl}$ & 01 \\
\hline & PTI & \\
\hline & $100 \%$ & 14 \\
\hline & $74-100 \%$ & 02 \\
\hline & $50 \%$ & 02 \\
\hline & Platelet count & \\
\hline & $1.5-4 \mathrm{lac} / \mathrm{mm}^{3}$ & 14 \\
\hline & $10,000-15,000 / \mathrm{mm}^{3}$ & 04 \\
\hline & TSH(Thyroid stimulating hormone) & \\
\hline & $66 \mathrm{MIU} / \mathrm{L}$ & 01 \\
\hline & $44 \mathrm{MIU} / \mathrm{L}$ & 01 \\
\hline & USG & \\
\hline & Normal & 15 \\
\hline & Polycystic ovaries & 03 \\
\hline
\end{tabular}

\begin{tabular}{ll}
\hline III. & Management \\
\hline Blood transfusion & 17 \\
High dose OCPs & 12 \\
High dose OCPs + Tranexmic acid & 03 \\
Progesterone + Tranexmic acid & 03 \\
\hline
\end{tabular}

Anovulatory bleeding was the cause in $50-74 \%$ of the patients requiring hospital admission as reported in the literature..$^{2,3}$ Incidence of dysfunctional uterine bleeding in adolescent menorrhagia varied from $69.5-74 \%$ in Indian literature. ${ }^{7,8}$ In the present review of 18 cases of severe puberty menorrhagia requiring indoor admission, $61 \%$ were diagnosed to be having abnormal uterine bleeding due to anovulation.

Acquired and congenital bleeding disorders are second most common cause of menorrhagia in adolescence girls. A population based prevalence study reported $0.8 \%$ prevalence of perceived bleeding symptoms including menorrhagia in young healthy females. ${ }^{9}$ Reported incidence of bleeding disorder in adolescent menorrhagia in past varied from $17-25 \%{ }^{5,10}$ However, the recent literature reports $10.4 \%$ prevalence of inherited bleeding disorders in teenagers with menorrhagia. ${ }^{11}$ Saxena $\mathrm{R}$ et al reported $15.3 \%$ of women with menorrhagia have an inherited bleeding disorder as the underlying cause. ${ }^{12}$ In present study five $(27 \%)$ patients presented with bleeding disorder i.e. three with thrombocytopenia and one each with VonWillebrand disease and leukemia. A retrospective analysis by Falcone et al found that $4.9 \%$ of admissions over a 10 -year period were secondary to coagulopathy. ${ }^{3}$ Bevan et $\mathrm{al}^{13}$ found $13 \%$ incidence of thrombocytopenia among all girls who presented for evaluation of menorrhagia but in the present study $16.6 \%$ had thrombocytopenia.

Von-Willebrand disease is characterized by an autosomal dominant pattern of inheritance and affects approximately $1 \%$ in the general population ${ }^{14}$ and $11.9-32 \%$ among women with menorrhagia..$^{11,15,16}$ Jennifer A. Bevan et al reported two cases of type I Von-Willebrand disease among 71 girls with adolescent menorrhagia. ${ }^{13}$ Initial management modalities of Von-Willebrand disease are blood transfusion and high dose oral contraceptive pills. Because concentration of Von-Willebrand factor (VWF) tend to increase with age, individual may become phenotypically normal as they grow-up. ${ }^{17}$ Alternative therapy for individuals with Von-Willebrand disease and platelet function desmopressin a synthetic analogue of vesopressin which in intranasal form increase the circulating levels of VWF and factor VIII. ${ }^{18}$ Our patient was managed with blood transfusion and responded to high dose of OC pills.

Hypothyroidism as a cause for menorrhagia has been debated. Prentice in his review of menorrhagia states that there is little evidence to link hypothyroidism with 
excessive menstrual loss. ${ }^{19}$ Scott JC et al had quoted incidence of menorrhagia in myxoedema patients $36 \%$ and menorrhagia many not infrequently be the presenting complaint. ${ }^{20}$ The menorrhagia associated with hypothyroidism respond promptly to the thyroid replacement, often in doses insufficient to correct manifestation of the condition. This suggests that thyroxine does have a direct effect on arterial and on hemostasis at menstruation.

Polycystic ovaries may be temporary in adolescent or may progress to full blown polycystic ovarian disease with hirsutism. ${ }^{6}$ Of three patients with anovulation who showed features of polycystic ovaries on ultrasonography, none of these had features of hyperandrogenism or hyperandrogenemia to label the diagnosis of polycystic ovarian disease. Hormonal therapy remains the most effective treatment for the puberty menorrhagia. More than $93 \%$ respond to medical treatment. ${ }^{2}$ In present study all except one responded to medical treatment. Intravenous administration of conjugated equine estrogen i.e (25 mg every four hourly) is highly effective in controlling uterine bleeding ${ }^{21}$ and is usually continued until bleeding has ceased which occurs within 24 hours in most of the cases. Continuation therapy is usually recommended and may be given in the form of oral equine estrogens in the doses of $2.5 \mathrm{mg}$ for $20-25$ days with addition of medroxyprogesterone acetate $10 \mathrm{mg}$ for the last seven days or in the form of OCPs. If the bleeding is not associated with severe symptoms combination OCPs in accelerating i.e. twice daily for one week followed by three weeks of regular dosing. For subsequent cycle control OCPs, cyclic oral medroxyprogesterone acetate or nor ethinderone acetate may be prescribed. ${ }^{21}$ In our study all except one patients responded to either combination oral contraceptive pills in high dose or progesterone.

\section{CONCLUSIONS}

Adolescent menorrhagia is common condition and can become serious requiring admission and blood transfusion. Most of the cases can be explained by anovulation but haematological, endocrinological or organic causes should be excluded by appropriate evaluation especially in those patients who present in menarche or are not responding to the treatment. Medical management is effective in most of the cases. Paediatricians, gynaecologists, adolescent health care provider should be aware of haematological and endocrinological problems can be associated with puberty menorrhagia not responding to routine treatment.

\section{REFERENCES}

1. DeVore GR, Owens O, Kase N. Use of intravenous premarin in the treatment of dysfunctional uterine bleeding. A double blind randomized control study. Obstet Gynecol. 1982; 59:28591.

2. Claessens EA, Cowell CA. Acute adolescent menorrhagia. Am J Obstet Gynecol. 1981; 139:277-80.

3. Falcone T, Des Jardins C, Bourque J, Granger L, Hemmings $\mathrm{R}$, Quiros E. Dysfunctional uterine bleeding in adolescents. J Reprod Med. 1994; 39:761-4.

4. O'Connell BJ. The pediatrician and the sexually active adolescent. Treatment of common menstrual disorders. Pediatr Clin North America. 1997; 44:1391-404.

5. Kadir RA, Economide DL, Sabin CA, Owens D, Lee CA. Frequency of inherited bleeding disorder in women with menorrhagia. Lancet. 1998; 351:485-9.
6. Debra A, Minjarez MD, Karen D, Bradshaw MD. Abnormal uterine bleeding in adolescents. Obstetrics \& Gynaecology Clinics of North America. 2000; $27: 72$.

7. Goswami S, Dutta R, Sengupta S. A profile of adolescent girls with gynecological problems. J Obstet Gynecol India. 2005; 55:353-5.

8. Ahuja R, Kriplani A, Chaudhary VP, Takkar D. VonWillebrand disease: A rare cause of puberty menorrhagia. Aust NZ J Obstet Gynaecol. 1995; 35:337.

9. Friberg B, Orno AK, Lindgren A, Lethagen S. Bleeding disorders among young women: population based prevalence study. Acta Obstet Gynecol Scand. 2006; 85:200-6.

10. Droegemuller W, Herbst AL, Mishell DR, Stenechever MA. Comprehensive Gynaecology St Louis MD: CV Mosby; 1987. p. 954-5. 
11. Jayasinghe $\mathrm{Y}$, Moore $\mathrm{P}$, Danath S, Campbell J, Monagle $\mathrm{P}$, Gorver S. Bleeding disorders in teenagers presenting with menorrhagia. Aus NZ J Obstet Gynaecol. 2005; 45:439-43.

12. Saxena R, Gupta M, Gupta PK, Kashyap R, Choudhary VP, Bhargava M. Inherited bleeding disorder in Indian women with menorrhagia. Hemophilia. 2003; 9:660-1.

13. Bevan JA, Malaney KW, Hillery CA, Gill JC, Montgomery RR, Scott JP. Bleeding disorder: A common cause of menorrhagia in adolescent. J Pediatrics. 2001; 138:856-61.

14. Werner EJ. Von Willebrand disease in children and adolescent. Pediatric Clin North America. 1996; 43:683-707.

15. Edlund M, Blomback M, Von Schoultz B, Andersson O. On the value of menorrhagia as a preductor for coagulation disorders. Am J Hematol. 1996; 53:234-8.
16. Scharrer I. Women with von-Willebrand disease. Hamostaseologie. 2004; 24:44-9.

17. Zimmerman TS, Ruggeri ZM. Von-Willebrand's disease. Human Pathol. 1987; 18:140-52.

18. Mannucci PM. Desmopressin in the treatment of bleeding disorders: In the first 20 years. Blood. 1997; 90:2515-21.

19. Prentice A. Medical management of menorrhagia. BMJ. 1999; 319:1343-5.

20. Scott JC, Mussey E. Menstrual patterns of myxedema. Am J Obstet Gynaecol. 1964; 90:161-5.

21. Strickland JL, Wall JW. Abnormal uterine bleeding in adolescents. Obstet Gynecol Clin N Am. 2003; 30:321-35. 